\title{
Redox Behavior of Crosslinked Polyaniline Films
}

\author{
José E. P. da Silva, Susana I. C. de Torresi and Marcia L. A. Temperini* \\ Departamento de Química Fundamental, Instituto de Química, Universidade de São Paulo, \\ CP 26077, 05599-970, São Paulo - SP, Brazil.
}

\begin{abstract}
Os processos redox da polianilina dopada secundariamente e dopada primariamente préaquecidas $\left(150{ }^{\circ} \mathrm{C}, 6-12\right.$ horas) foram investigados pela espectroscopia Raman ressonante in-situ. Os espectros Raman do polímero dopado secundariamente mostram uma maior dependência com o aumento do potencial do que o polímero dopado primariamente pré-aquecido. Estes diferentes comportamentos foram atribuídos à presença de diferentes graus de ligações cruzadas nos polímeros. A presença de diferentes quantidades de ligações cruzadas foi confirmada por análise termogravimétrica, espectroscopia UV-vis e voltametria cíclica.
\end{abstract}

The redox processes of secondarily doped and the pre-heated primarily doped polyaniline $\left(150^{\circ} \mathrm{C}, 6-12 \mathrm{~h}\right)$ were investigated by in-situ resonance Raman spectroscopy. Raman spectra of secondarily doped polymer is more dependent on potential than those observed in the pre-heated primarily doped polymer. These different behaviors were attributed to the presence of different degree of crosslinking in the polymers. The presence of different amounts of crosslinking was confirmed by thermogravimetric analysis, UV-vis spectroscopy and cyclic voltammetry.

Keywords: polyaniline, Resonance Raman, crosslinking.

\section{Introduction}

The secondary doping effect ${ }^{1,2}$ phenomenologically consists in the treatment of a polymer already doped with a functionalized organic acid with an organic solvent, for example, polyaniline doped with camphorsulfonic acid dissolved in $m$-cresol.

This effect produces an increase in the conductivity $\left(\sim 400 \mathrm{~S} . c m^{-1}\right)$ of polyaniline and conformational changes in the polymeric chains from the coil form to the expanded one.

It was observed by ex-situ Raman spectroscopy and ESR ${ }^{3}$ that in addition to a conformational effect a conversion of quinoid structures into semiquinoid ones also occurs in the same oxidation state of polyaniline (emeraldine form), a process called internal redox reaction ${ }^{4}$. Scherr et a ${ }^{5}$ and Rodrigue et $\mathrm{al}^{6}$ have shown that temperature produces crosslinked polymers leading to the formation of structures others than radical ones, such as ternary cycled nitrogen producing "phenazine like" segments. Recently, Resonance Raman Spectroscopy7,8 has confirmed the presence of cyclized nitrogen structures in heated samples and the Raman bands at $c a .574,1380$ and 1630

e-mail: mlatempe@quim.iq.usp.br

Presented at the XI Simpósio Brasileiro de Eletroquímica e Eletroanalítica, Maragogi - AL, Brazil, April 5-9, 1999. Guest editor: Luis Alberto Avaca. $\mathrm{cm}^{-1}$ have been assigned to these segments. Moreover, the same bands were observed in the Raman spectrum of polyaniline treated with Fenton's reagent, a well known reticulating agent.

The aim of this work is to follow the electrochemical behavior of secondarily doped and pre-heated primarily doped polyaniline by cyclic voltammetry and resonance Raman spectroscopy. A more detailed explanation of the convertion of structures in the emeraldine form (internal redox reaction) and other processes occurring in the polymers heated or treated with $m$-cresol are presented.

\section{Experimental}

Polyaniline (PANI) was electrochemically deposited onto gold electrode by cyclic voltammetry from a $0.5 \mathrm{~mol} \mathrm{~L}^{-1}$ aniline $+1.0 \mathrm{~mol} \mathrm{~L}^{-1}$ camphorsulfonic acid (HCSA) solution by linear potential sweeps between $-0.2 \mathrm{~V}$ and $+0.75 \mathrm{~V}$ at $50 \mathrm{mV} \mathrm{s}^{-}$ 1. A platinum wire was used as a counter electrode and all potentials are referred to the $\mathrm{Ag} / \mathrm{AgCl}$ electrode. The heating of the films was carried out in an oven at a constant temperature of $150^{\circ} \mathrm{C}$ for $6-12 \mathrm{~h}$.

Cyclic voltammograms of polyaniline films before and after heating were carried out in a monomer free $0.78 \mathrm{~mol} \mathrm{~L}^{-1}$ HCSA solution using Autolab PGSTAT30 from ECOCHEMIE. The PANI/CSA was secondarily doped after dissolution 
of the polymer into $m$-cresol $\left(1.1 \mathrm{mg} \mathrm{mL}^{-1}\right)$. The mixture was treated in ultrasonic bath for $10 \mathrm{~h}$ and then filtered in order to obtain a limpid solution. Films were prepared from this solution by "dip coating" technique onto gold electrode.

In-situ Resonance Raman spectra with 632.8 nm exciting radiation (He-Ne laser, Spectra Physics, mod 127) were recorded in a Renishaw Raman Imaging (System 3000) containing an Olympus metallurgical microscope and a CCD detector. Laser power was always kept below $0.7 \mathrm{~mW}$ at the sample to avoid sample degradation. The potential was fixed for each spectrum with an EG\&GPAR 362 potentiostat/galvanostat.

Thermogravimetric analyses were performed in a HiResTM TGA 2950 (T.A. Instruments).

UV-vis spectra were performed with a Hewlett-Packard 8453 diode array spectrophotometer.

\section{Results and Discussion}

Figure 1 shows ex-situ Raman spectra of different preparations of polyaniline. Figures 1A and 1B show Raman spectra of primarily and secondarily doped polyaniline, respectively. Results indicate an increase in the relative intensity of bands assigned to semiquinoid structures ${ }^{3,9-13}$ at 1330,1510 and $1600 \mathrm{~cm}^{-1}$, with the corresponding decrease of the relative intensity of the bands assigned to quinoid structures 3 ,913 at 1480 and $1580 \mathrm{~cm}^{-1}$. Another fact that can be observed from the figures is the appearance of bands located at 574 , 1380 and $1643 \mathrm{~cm}^{-1}$ for secondarily doped samples. These latter bands are more intense in the Raman spectra of preheated primarily doped polyaniline (Figure 1C).
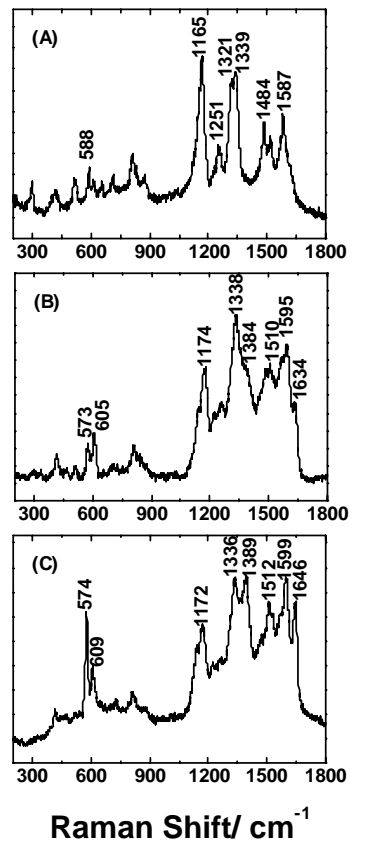

Figure 1. Resonance Raman spectra of: (A) primarily doped PANI/ CSA, (B) secondarily doped PANI/CSA/ $m$-cresol and (C) pre-heated primarily doped PANI/CSA $\left(150{ }^{\circ} \mathrm{C}, 12 \mathrm{~h}\right) . \lambda_{0}=632.8 \mathrm{~nm}$.

Figure 2 shows the in-situ Raman spectra of secondarily doped polyaniline. In the $-0.2 \mathrm{~V}$ and $+0.2 \mathrm{~V}$ potential range, the resonance Raman spectra are similar to those obtained ex-situ for the same polymer in the emeraldine form. At $+0.5 \mathrm{~V}$ the oxidation of secondarily doped polymer begins to change the Raman spectra. A decrease in the relative intensity of the bands at 574, 1176, 1330, 1380, 1602 and $1633 \mathrm{~cm}^{-1}$ can be observed. This fact indicates the diminution of reduced and semi-oxidized segments which occurs together with the increase of the bands assigned to oxidized structures and located at 1169, 1495, 1585 and $1620 \mathrm{~cm}^{-1}$. The Raman spectrum obtained at +0.75 $\mathrm{V}$ indicates that the polymer is completely oxidized presenting the characteristic bands of pernigraniline form and the loss of the band at $1330 \mathrm{~cm}^{-1}$, corresponding to polaronic structures.
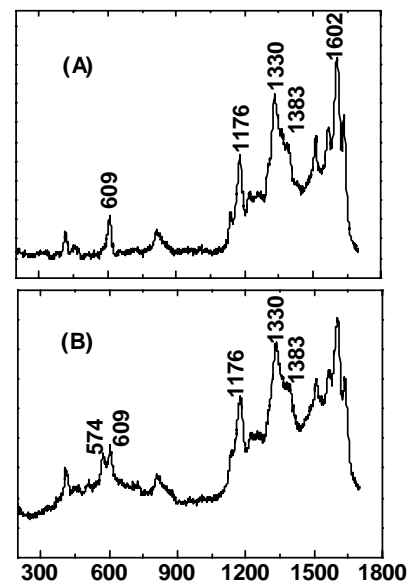

Raman Shift/ $\mathrm{cm}^{-1}$

Figure 2. In-situ Resonance Raman spectra of secondarily doped PANI/CSA/ $m$-cresol film as a function of potential: (A) $-0.2 \mathrm{~V}$, (B) $+0.2 \mathrm{~V},(\mathrm{C})+0.5 \mathrm{~V}$ and $(\mathrm{D})+0.75 \mathrm{~V} . \lambda_{0}=632.8 \mathrm{~nm}$.

In Situ Resonance Raman spectra of pre-heated primarily doped polyaniline (Figure 3 ) show that the oxidation process of the polymer is more difficult because the bands assigned to the vibrational modes of reduced and semioxidized structures do not decrease with the potential as observed for secondarily doped samples (Figure 2). It must also be emphasized that, even at more positive potentials, the bands at 574, 1380 and $1643 \mathrm{~cm}^{-1}$ are always present in the spectrum, differently from what was observed in the Raman spectra of secondarily doped polymer. As it can be observed, the relative intensity of these bands is potential dependent indicating that the structures formed are electroactive. Recent results show that these vibrational modes can be assigned to "phenazine-like" structures formed during heating due to interchain interactions ${ }^{8}$. The 
formation of this type of structures has already been suggested by Gènies et al ${ }^{14}$ to explain the reticulation reaction of polyaniline films.

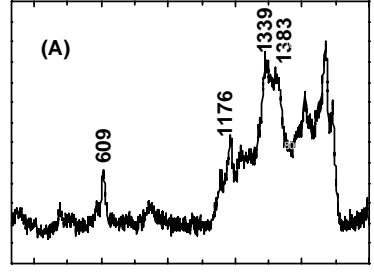

(B)

$$
\text { (B) }
$$

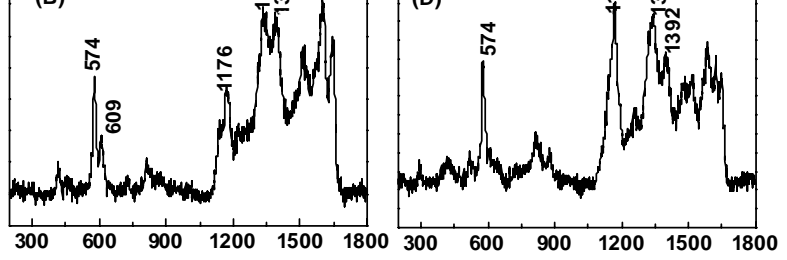

Raman Shift $/ \mathbf{c m}^{-1}$
Figure 3. In-situ Resonance Raman spectra of pre-heated primarily doped PANI/CSA film as a function of potential: (A) $-0.2 \mathrm{~V}$, (B) $+0.3 \mathrm{~V},(\mathrm{C})+0.5 \mathrm{~V}$ and $(\mathrm{D})+0.75 \mathrm{~V} . \lambda_{0}=632.8 \mathrm{~nm}$.

These facts can be explained considering that the preheated primarily doped polymer has a more crosslinked structure than secondarily doped PANI, hindering the effective oxidation of the polymer.

The presence of different degrees of crosslinking in different preparations was confirmed by TGA analyses? The amount of residue, in the case of pre-heated polyaniline $(53 \%)$, is greater than those obtained for primarily $(26 \%)$ and secondarily doped $(37 \%)$ samples, showing that the polymer is more reticulated 15 .

Results obtained by in-situ UV-vis spectroscopy and cyclic voltammetry also put in evidence the less effective oxidation process in pre-heated doped polyaniline. UV-vis spectra of primarily doped polyaniline (Figure 4) show that at $+0.75 \mathrm{~V}$, the band centered at $675 \mathrm{~nm}$, in the pre-heated primarily doped polyaniline spectra (Figure 5), is observed at $730 \mathrm{~nm}$. This small shift towards lower energies at positive potentials indicates a greater stabilization of the emeraldine form in the polymer, which is consistent with the results obtained by in-situ resonance Raman spectroscopy.

Voltammetric data (Figure 6) show a diminution of charge for the pre-heated polymer due to the formation of crosslinking. From the voltammograms the electric charge can be calculated giving $95.4 \mathrm{mC} \mathrm{cm}^{-2}$ for primarily doped polyaniline and $75.6 \mathrm{mC} \mathrm{cm}^{-2}$ for the pre-heated samples. These bonds make the polymer less porous, hindering the oxidation because the swelling of the polymer by the electrolyte is lower and consequently, the anion exchange is reduced.

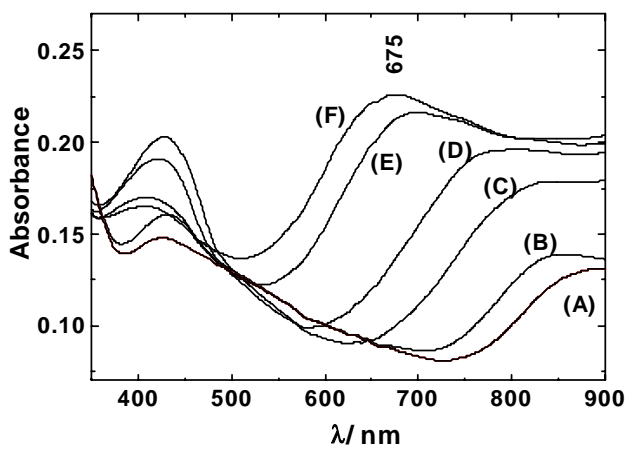

Figure 4. In-situ UV-vis spectra of primarily doped PANI/CSA film as a function of potential: (A) $-0.2 \mathrm{~V},(\mathrm{~B})+0.2 \mathrm{~V}$, (C) $+0.3 \mathrm{~V}$, (D) $+0.5 \mathrm{~V},(\mathrm{E})+0.75 \mathrm{~V}$ and $(\mathrm{F})+0.8 \mathrm{~V}$.

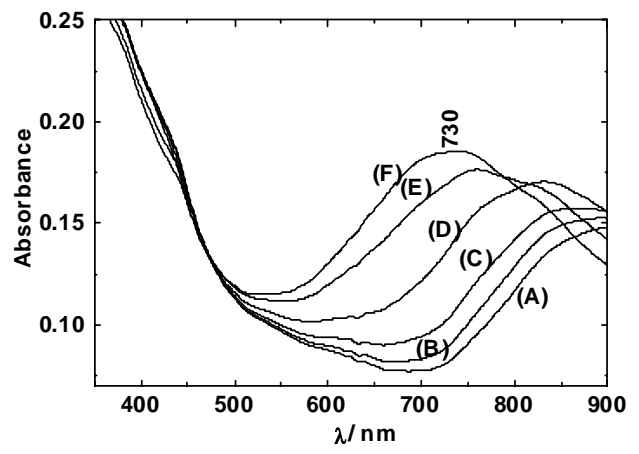

Figure 5. In-situ UV-vis spectra of pre-heated primarily doped PANI/CSA film as a function of potential: (A) $-0.2 \mathrm{~V},(\mathrm{~B})+0.2 \mathrm{~V}$, (C) $+0.3 \mathrm{~V}$, (D) $+0.5 \mathrm{~V}$, (E) $+0.75 \mathrm{~V}$ and $(\mathrm{F})+0.8 \mathrm{~V}$.

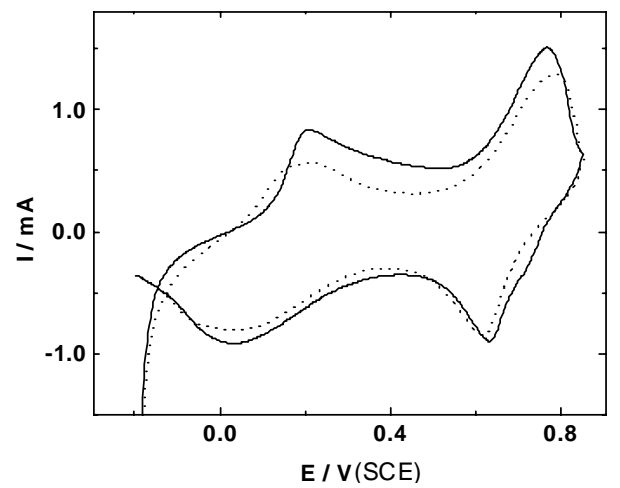

Figure 6. Cyclic voltammograms of polyaniline: $(-)$ before heating and (......) after heating at $150^{\circ} \mathrm{C}$ for $12 \mathrm{~h}$.

On the other hand, another effect to be considered is the change of conductivity due to the diminution of conjugation produced by crosslinking.

The higher stability of emeraldine form when the material is heated can be proved, in this case, by the depolarization of the first redox process assigned to the leucoemeraldineemeraldine transition, and the polarization of the second redox process, assigned to emeraldine-pernigraniline transition. This fact indicates that polyaniline in the semi-oxidized form is stable in a wider potential region in the case of pre-heated samples. 


\section{Conclusions}

In situ Resonance Raman and electrochemical results are consistent with the formation of crosslinked structures in polyaniline films when heated. The less effective oxidation process of heated films, even at high positive potentials, is due to a low swelling of the polymer by the electrolyte. This is corroborated by the observation of the Raman bands corresponding to polaronic segments at high positive potentials, in contrast to that observed for non-heated samples, in which the increase of Raman bands of imine structures were observed. Electrochemical data have shown that thermal treatment leads to a stabilization of the emeraldine form due to the depolarization of the leucoemeraldineemeraldine couple, together with the polarization of the emeraldine-pernigraniline redox process.

\section{Acknowledgements}

Authors are indebted to Brazilian Agencies FAPESP (Procs. N ${ }^{\circ}$ 98/07624-8 and 98/15686-3), CNPq and CAPES.

\section{References}

1. MacDiarmid, A. G.; Epstein, A. J. Synth. Met. 1994, 65, 103.

2. Xia, Y.; Wiesinger, J. M.; MacDiarmid, A. G. Chem. Mater. 1995, 7, 443.

3. Silva, J. E. P.; Torresi, S. I. C.; Temperini, M. L. A.
Electrochim. Acta 1999, 44, 1887.

4. Stafström, S.; Bredas, J. L.; Epstein, A. J.; Woo, H. S.; Tanner, D. B.; Huang, H. S.; MacDiarmid, A. G. Phys. Rev. Lett. 1987, 59, 1464.

5. Scherr, E. M.; MacDiarmid, A. G.; Manohar, S. K.; Masters, J. G.; Sun, Y.; Tang, X.; Druy, M. A.; Glatkowski, P. J.; Cajipe, V. B.; Fisher, J. E.; Cromack, K. R.; Jozefowicz, M. E.; Ginder, J. M.; McCall, R. P.; Epstein, A. J. Synth. Met. 1991, 41, 735.

6. Rodrigue, D.; Riga, J.; Verbist, J. J.J. Chim. Phys.1992, 89, 1209.

7. Silva, J. E. P. Master Thesis; Universidade de São Paulo 1999.

8. Silva, J. E. P.; Faria, D. L. A.; Torresi, S. I. C.; Temperini, M.L.A.Macromolecules 2000 (in press).

9. Louarn, G.;Lapkowski, M.; Quillard S.;Pron A.; Buisson, J. B.; Lefrant S.J. Phys. Chem. 1996, 100, 6998.

10. Quillard, S.; Berrada K.; Louarn G.; Lapkowski, M.; Lefrant S.; Pron, A. New. J. Chem. 1995, 19, 365.

11. Sariciftci, N. S.; Kuzmany, H Synth. Met. 1987, 21, 157.

12. Cochet, M; Corraze, B.; Quillard, S.; Buisson, J. P.; Lefrant, S.; Louarn, G. Synth. Met. 1997, 84, 757.

13. Furukawa, Y.; Hara, T.; Hyodo, Y.; Harada, I. Synth. Met. 1986, 16, 189.

14. Gènies, E. M.; Lapkowski, M.; Penneau, J. P. J. Electroanal. Chem., 1988, 249, 97.

15. Wang, X. H.; Geng, Y. H.; Wang, L. X.; Jing, X.B.; Wang, F. S.Synth. Met. 1995, 69, 263.

Received: June 15, 1999

FAPESP helped in meeting the publication costs of this article. 